\title{
El reducido espacio de la solidaridad en los tipos de la parte especial del Derecho penal chileno*
}

\author{
Luis Emilio Rojas Aguirre*
}

\section{RESUMEN}

El trabajo ofrece un panorama de las normas contenidas en la parte especial de la legislación penal que se relacionan con la idea general de solidaridad. Una aproximación al fundamento de cada norma, sin embargo, muestra que este, en todos los ejemplos mencionados salvo en el tipo de omisión de socorro, se aparta de una consideración exclusiva de solidaridad intersubjetiva. La pretensión del trabajo es todavía básicamente descriptiva y busca identificar las normas que tendrian un fundamento exclusivo en el deber general de solidaridad intersubjetiva.

Deber de solidaridad - parte especial - exposición

\section{The reduced space of solidarity in the types of the Chilean Criminal Law's special part}

\begin{abstract}
This paper offers an overview of the norms contained in the special part of the criminal legal system that relate with the general idea of solidarity. An approximation to the basis of each norm, however, shows that in all of the examples mentioned, except for the type of omission of rescue, it departs from an exclusive consideration of intersubjective solidarity. The ambition of this document is still basically descriptive and seeks to identify the rules that would have an exclusive foundation in the general duty of intersubjective solidarity.
\end{abstract}

Duty of solidarity - special part - exposition

* Licenciado en Ciencias Jurídicas y Sociales, Universidad de Chile. Doctor en Derecho, Universidad de Friburgo, Alemania. Profesor de derecho penal, Universidad Alberto Hurtado. Correo electrónico: lurojas@uahurtado.cl

Trabajo escrito en el marco del proyecto Fondecyt N. 1150178 sobre "Líneas básicas de una dogmática de los delitos propios de omisión: una aproximación al deber de solidaridad y al significado de su infracción", en el que el autor cumple el rol de investigador principal; coinvestigadora en el proyecto es la Dra. María Soledad Krause; agradecimientos al ayudante de investigación, Claudio Quintana.

** Artículo recibido el 29 de agosto de 2017 y aceptado para su publicación en este número el 18 de enero de 2019. 


\section{INTRODUCCIÓN}

E l objeto del presente trabajo se reduce a ofrecer un panorama de los tipos de la parte especial del Derecho penal chileno que describen un hecho cuyo injusto puede explicarse por la infracción a un deber general de solidaridad. Lo que se busca con este ejercicio es identificar las normas cuyo fundamento se explica solamente por consideraciones de solidaridad. Este esfuerzo sirve para así delimitar el conjunto de normas que exige una indagación en el problema filosófico-político del fundamento y ubicación de tal principio en un Estado de Derecho regido por la idea de libertad ${ }^{1}$, cuestión que se pretende abordar con mayor profundidad en otro lugar.

Sin perjuicio de lo dicho, y para los efectos de la presente exposición, resulta no obstante conveniente explicitar antes una noción siquiera general de la idea de solidaridad. En este punto, y con ese fin, se entiende bajo tal idea un vínculo entre personas que se encuentran previamente unidas entre sí por determinadas características comunes-como historia, convicciones e intereses- y que insta a responder recíprocamente uno para el otro $^{2}$. Así comprendida esta idea, es posible adelantar que una revisión de la legislación penal vigente arroja como conclusión que su espacio en los tipos de la parte especial es extremadamente reducido, es decir, estamos frente a una legislación muy poco solidaria. Lo dramático es que esta expresión mínima de la solidaridad tampoco se debe a que la legislación penal sea extremadamente liberal. Si se tiene presente la sistemática del Código Penal chileno (en adelante: CP), cuya parte especial comienza con los delitos contra la seguridad del Estado, sigue con la protección de la libertad básicamente en su dimensión ambulatoria mediante las normas respecto de delito de secuestro, relega los delitos contra los derechos individuales de la persona (vida, integridad física, propiedad) a la parte final del Código y, sobre todo, no incluye un delito de coacciones, al mismo tiempo que lo reduce a una mera falta en el art. 494 N. 16, el diagnóstico debería concluir que esta legislación tampoco es una expresión decidida de liberalismo político ${ }^{3,4}$.

${ }^{1}$ Cfr. Wilenmann, 2014a, pp. 122 y ss., quien opone el principio de solidaridad al concepto formal de autonomía, sin que se excluyan entre sí: pues, la solidaridad "complementa o completa la libertad configurada mediante la autonomía formal”.

${ }^{2}$ Cfr. Bayertz, 1998, p. 21.

${ }^{3}$ De otra opinión GuZMÁn, 2013, pp. 107 y s., aunque fundado más bien en las "ostensibles muestras" de liberalismo político en la parte general del Código.

${ }^{4}$ Es importante tener presente que en el mensaje del CP, dirigido por el gobierno al Congreso en 1873, se pone en evidencia una preocupación encaminada más bien a proteger la institución y organización del Estado antes que los derechos y garantías de las personas. En este sentido, por ejemplo, en el párrafo XIV del discurso, se manifiesta que en la clasificación de los delitos se tomó como punto de partida a "la organización misma de la sociedad a cuya estable conservación debe proveer ante todo la ley”. A continuación, y como consecuencia de lo anterior, se declara que se examinaron aquellos hechos que importaban una merma a las bases del Estado (párrafo XV), para luego, recién, ocuparse de los preceptos que asegurarían las libertades individuales y todos los derechos que especialmente garantiza la Carta Fundamental, aunque solamente como consecuencia de asegurar el orden interior del Estado (párrafo XVI). Es decir, la protección de estos intereses obedeció más bien al resguardo del orden del Estado que a una preocupación genuina de corte liberal (CP, Mensaje, párrafos XIV, XV y XVI, 1874), Código Penal, República de Chile, "Mensaje”. 
Sin embargo, ahora no se tiene la pretensión de juzgar cuán liberal es la legislación penal, sino que solamente de identificar el espacio que ocupa la solidaridad en su parte especial. En este sentido, entonces, la indagación siguiente ya supone que tal idea cumple algún rol en este marco, vale decir, parte de la premisa de la existencia de ese principio también en este contexto legislativo. Este supuesto, empero, no es para nada evidente, de ahí la necesidad de explicitarlo.

En este orden de consideraciones, si el contenido de la idea de solidaridad reside en un vínculo entre personas que comparten ciertas características comunes previas, derivadas de la pertenencia a una misma comunidad política, sucede que tal vínculo ya existía en el origen mismo del Estado de Derecho. Mas para volverse consciente de este origen, es necesario tomar distancia de una pretensión de fundamentación absoluta del Estado liberal de Derecho, en tanto ella genera la impresión de que este se habría desarrollado a partir de la nada - "el futuro necesita origen"5 - . Ocurre que la justificada concentración en la legitimación y desarrollo del Estado de Derecho hizo tempranamente olvidar la existencia de dicho vínculo originario y, al mismo tiempo, llevó a pensar que podía ser protegido suficientemente con la prohibición también originaria del neaminem laedere y sus manifestaciones. En esta concepción predominante, el Estado quedaba reducido a un mero vigilante del sagrado respeto a esta prohibición. Recién a fines del siglo 19, con el surgimiento y desarrollo del Estado social de Derecho, se hizo gradualmente consciencia de que dicho vínculo originario exigía una protección adicional mediante contribuciones recíprocas entre los ciudadanos ${ }^{6}$. Cuáles contribuciones recíprocas son necesarias y exigibles, eso depende de una definición del legislador democrático, sometida a férreos límites precisamente por su falta de obviedad en un Estado liberal de Derecho $^{7}$. Una de estas contribuciones recíprocas, que es calificada de básica y mínima cuando un ciudadano se encuentra en una situación de peligro existencial, en el sentido de que esta pone en riesgo la existencia misma del vínculo originario, radica en el deber general de solidaridad ${ }^{8}$.

\footnotetext{
${ }^{5}$ Cfr. Marquard, 2015, pP. 16 y ss., la vida del hombre es demasiado corta para fundamentaciones totales, inevitablemente este debe "conectar" (Anknüpfen) con el origen, con la tradición.

${ }^{6}$ Cfr. Depenheuer, 1991/2009, pp. 166 y ss.

7 Depenheuer, 1991/2009, pp. 183 y ss., 219 y ss., la solidaridad resulta exigible solo mediante regulación legal y al mismo tiempo limitada por los derechos fundamentales.

${ }^{8}$ Hegel, 1970, § 127, en la sección sobre moralidad, reconoce un derecho de necesidad, pero momentáneo y limitado a la situación de conflicto entre el peligro existencial del sujeto y la propiedad del otro; en cambio, la ayuda para superar la pobreza y las necesidades de toda clase, es tratada posteriormente en el acápite sobre eticidad, a propósito de la policía y luego de la corporación ( $\$ \$ 242$ y ss.). Probablemente por ser dicha contribución básica y mínima, RAwLS, 1975, p. 135 y s., califica este deber de "natural” y lo menciona junto al deber de no dañar a otro; posteriormente, a propósito del concepto de distribución de bienes económicos y sociales (p. 349), advierte que el fin del Derecho penal radica en asegurar los deberes naturales básicos y que, evidentemente, este nada tiene que ver con dicha distribución. Esta diferenciación de deberes, que ya traza antes la filosofía moral y política, se pierde de vista cuando la dogmática jurídicopenal trata conjuntamente e incluso confunde, bajo la idea general de solidaridad, el deber básico de auxilio con un deber moral de promover el bienestar del otro.
} 
Este deber de solidaridad tiene una faz pasiva, que explica el fundamento normativo de la justificación en la hipótesis del estado de necesidad agresivo -art. 10 N. 7 CP9 -. Y tiene asimismo una faz activa en la forma de un deber de auxilio, cuya infracción funda la responsabilidad por el delito de omisión de socorro -art. 494 N. 14 CP-. En su faz activa, por consiguiente, la principal forma de infracción a este deber es mediante omisión. De ahí que la búsqueda se inicie con los principales tipos que describen una omisión-delitos propios de omisión-.

Respecto del trasfondo de las reflexiones precedentes, a continuación se exponen solamente las manifestaciones del deber general de solidaridad en su faz activa, esto es, cuya infracción puede configurar el injusto de un delito tipificado en la parte especial del Derecho penal.

\section{El PARADIGMA DEL TIPO DE OMISIÓN DE SOCORRO}

(ART. 494 N. 14 CP)

En este sentido, parece conveniente empezar con el paradigma del tipo general de omisión de socorro, para luego ver cómo otras normas se apartan tendencialmente de él y, en esa medida, se apoyan en consideraciones distintas del deber general de solidaridad:

Art. 494 N. 14 CP: "El que no socorriere o auxiliare a una persona que encontrare en despoblado herida, maltratada o en peligro de perecer, cuando pudiere hacerlo sin detrimento propio".

Es bien sugerente que este paradigma se encuentre relegado por el CP al capítulo de las faltas y, además, que la realización de su tipo se castigue con una pena de multa ${ }^{10}$. Pues, no obstante que el texto de la ley hace referencia nada menos que a una

${ }^{9}$ Van Weezel, 2016, pp. 223 y ss. También, Wilenmann, 2014b, pp. 221-222, 234-235.

${ }^{10}$ La historia del tipo de omisión de socorro puede pesquisarse en las sesiones de trabajo de la comisión redactora del Código Penal de 1874. Específicamente, en las sesiones número 107, 108, 109 y 110 , a partir de estas es posible inferir que dicha norma fue incorporada al programa criminal chileno mediante una transcripción textual del art. 486 N. 12 del Código Penal español de 1850. En efecto, en la primera de estas sesiones comenzó la discusión sobre el Libro III del CP, concerniente a las faltas, advirtiéndose que únicamente se tipificarían aquellas que afectaran a la seguridad y salubridad públicas. A continuación, en las sesiones 108 y 109, se dio inicio a la discusión de las faltas graves, sin referencias explícitas al precepto en cuestión. Luego, en la sesión 110, se mencionó por primera vez el artículo en comento, con la numeración 479 N. 12, señalándose en las actas que "Los incisos 11, 12, 13 y 14 (del art. 479) fueron aprobados, sin alteración alguna [...]”, transcribiendo expresamente el artículo del CP español de 1850, ver: CHILE, Valparaíso, 1974, pp. 445-450 (en adelante, para referirse a las actas de la comisión redactora se usará la siguiente abreviatura: ASCR. N. Fecha). No obstante, el origen histórico del precepto se remonta ya a un supuesto de omisión incluido en la Ley XVI, Título VIII, Partida VII, de las Siete Partidas de Alfonso el Sabio, según el cual se castigaba la omisión de socorro por parte de siervos, sirvientes e hijos respecto de sus señores o padres, respectivamente. Ahora bien, esta hipótesis ha sido calificada como un origen difuso del supuesto actual, ya que el deber estaba dirigido a sujetos especiales y no a cualquiera, cfr. Aráuz, 2006, p. 25. Posteriormente, 
situación de peligro existencial, esto es, a una situación de peligro incluso para la vida de la persona y, por consiguiente, cuya norma puede ser interpretada como dirigida a la protección de este bien jurídico ${ }^{11}$, contempla una pena irrisoriamente baja. Esta forma de regulación solo puede explicarse como un reconocimiento limitado de la existencia de un deber general de socorro, cuya infracción es valorada muy por debajo de la lesión a deberes negativos, que son manifestaciones específicas de la prohibición originaria del neaminem laedere, y de la infracción de deberes positivos especiales, que tienen un estatus equivalente a los deberes negativos ${ }^{12}$. A todas luces, la inclusión de este deber general es sumamente restringida, en tanto su cumplimiento se supedita a una situación de peligro existencial que se presenta solamente fuera de la ciudad - "en despoblado"- y, además, que resulta exigible siempre que pueda prestarse el auxilio sin menoscabar los derechos propios del sujeto.

\section{Otras Figuras Relacionadas CON LA IDEA DE SOlIDARIDAD EN EL Código Penal (ART. 494 N. 13 y ART. 496 N. 2)}

Otra expresión muy limitada de la solidaridad puede encontrarse en la falta del art. 494 N. 13, que complementa las normas sobre delito de abandono de los artículos 346 a $352 \mathrm{CP}:$

Art. 494 N. 13: "El que encontrando perdido o abandonado a un menor de siete años no lo entregare a su familia o no lo recogiere o depositare en lugar seguro, dando cuenta a la autoridad en los dos últimos casos".

La ubicación de los delitos de abandono en el capítulo de los ilícitos contra el orden de la familia, la moralidad pública y ahora también la integridad sexual, revela que el interés originario del Código Penal radicaba en la protección de la familia. Sin embargo, esta ubicación sistemática no le impide a la doctrina reinterpretar estas normas desde una perspectiva moderna de protección a bienes jurídicos, como la vida o la salud. Según esta relectura, estos tipos de la parte especial describirían delitos de peligro concreto para la vida o la salud de la persona abandonada ${ }^{13}$. Su ubicación sistemática tampoco es óbice a una propuesta de normativización del fundamento de legitimación de estas normas

ya en el marco de la codificación, es posible identificarlo en el Código Penal español de 1822, específicamente en los artículos 123 y 698 del mismo, cfr. Aráuz, 2006, p. 25; RodríGuez, 1996, p. 25. Luego, el precepto de la omisión de socorro vuelve a aparecer en el Código Penal de 1848 como art. 472 N. 12 y, en la reforma de 1850 , como art. 486 N. 12, sin cambios de fondo (lamentablemente, no existen actas de la elaboración de este Código Penal, ver: AnTón, 1965, p. 486). Finalmente, esta versión del tipo es la que aparecerá en el catálogo de faltas del CP de 1874, como art. 494 N. 14.

11 Politoff et al., 1993, p. 277; Matus y Ramírez, 2017, pp. 215 y ss.

${ }^{12}$ Cfr. Wilenmann, 2016, pp. 286 y ss.

13 Politoff et al., 1993, pp. 266 y ss. 
desde el punto de vista de un deber general de solidaridad, al menos para las hipótesis típicas de abandono cometido por cualquiera -art. 346 (niño menor de 7 años en lugar no solitario) y art. 349 (niño menor de 10 años en lugar solitario) ${ }^{14}$-. Conforme con esta lectura posible, el tipo del art. 494 N. 13 CP describiría una hipótesis de omisión cuyo injusto radica en la infracción de un deber general de solidaridad en su faz activa ${ }^{15}$.

Sin embargo, la forma en que el tipo del art. 494 N. 13 describe la conducta de omisión, en los términos de no "entregar" a la familia o de no "recoger o depositar" en lugar seguro al niño menor de 7 años, pone en duda ya la interpretación del deber subyacente al tipo desde una óptica de "solidaridad intersubjetiva", i.e. entre personas. Pues, se entrega, recoge o deposita a un objeto, mas no a una persona. La exigencia de que se entregue el niño a la familia o que, junto con recogerlo o depositarlo en lugar seguro, se dé "cuenta a la autoridad" -v.gr.: estatal- podría incluso ser interpretada en el sentido de una colaboración con el cumplimiento de los deberes de tutela de la autoridad familiar o estatal, más que de protección a la persona del niño. Ahora bien, si uno soslaya lo observado y al mismo tiempo parte de la interpretación del deber a partir de una posición de "solidaridad intersubjetiva", bajo este supuesto resulta bien difícil justificar el tratamiento disímil para con un niño de 7,8 o 9 años de edad que se encuentra perdido o abandonado en un lugar solitario, en cuyo caso la infracción del deber no se encuentra sancionada penalmente, pero sí el abandono del mismo en tal clase de lugar -art. $349 \mathrm{CP}^{16}$ - Una vez más, y aún bajo ese entendido, se trataría de un reconocimiento muy limitado a tal deber en su ámbito de aplicación.

Otro ejemplo de reconocimiento del deber general de solidaridad, pero también limitado en su alcance ahora por encontrarse supeditado el cumplimiento del mismo a un requerimiento previo de la autoridad, se encuentra en la falta del art. 496 N. 2 CP:

Art. 496 N. 2: "El que pudiendo, sin grave detrimento propio, prestar a la autoridad el auxilio que reclamare en casos de incendio, inundación, naufragio u otra calamidad, se negare a ello".

Es interesante hacer notar que el supuesto fáctico del deber consiste aquí, a diferencia de los dos ejemplos precedentes, en una situación de peligro general para la comunidad. En cambio, en el tipo de omisión de socorro del art. 494 N. 14, el supuesto fáctico del deber radica en una situación de peligro puramente individual. Acá se trata de una situación de peligro común, frente a ella la norma presupone la competencia preferente de

${ }^{14}$ Cfr. Navas, 2015, p. 688. Es importante tener presente que el autor distingue los supuestos en comento, en el siguiente sentido; por una parte, señala como fundamento del injusto contenido en el art. 346 , la infracción de deberes positivos de carácter general; por otra, señala como fundamento del art. $347 \mathrm{CP}$, la infracción de deberes negativos originados por una asunción previa, cuyo reconocimiento estaría incluido en la frase "o personas que tuvieren al niño bajo su cuidado", de donde se extraería que personas que han asumido dicho compromiso lo han vulnerado.

${ }^{15}$ En cuanto al origen histórico de esta norma, se señala que fue incorporada en las mismas sesiones, y de igual forma, que el art. 494 N. 14 CP, ver nota número 10.

${ }^{16}$ Cfr. Matus y Ramírez, 2017, p. 215. 
la autoridad para intervenir. Esta clase de situaciones de peligro para bienes jurídicos de la comunidad son asunto preferente del Estado y sus órganos. Sin embargo, para hacerles frente de manera eficaz, puede ser necesario exigir la colaboración de los ciudadanos. El Estado delega, entonces, en el ciudadano una parte de las tareas necesarias para enfrentar la situación de peligro general, delegación que se convierte en esta situación excepcional en un deber cuya justificación deriva de la condición del sujeto de ser miembro de la misma comunidad que se encuentra en peligro ${ }^{17}$.

Lo interesante es que esta separación entre el supuesto fáctico del peligro individual, descrito por el tipo de omisión de socorro del art. 494 N. 14, y el presupuesto de la situación de peligro general, característico de este tipo del art. 496 N. 2 CP, parte de la premisa al menos de que el alcance del deber subyacente a una y otra norma es diferente $^{18}$. Pues el deber cuyo incumplimiento configura el injusto de la omisión de socorro descrita en el art. 494 N. 14 se infringe en desmedro de la víctima de la situación de peligro individual, mientras que el deber cuya infracción funda el injusto del tipo del art. 496 N. 2 CP se incumple frente al Estado y a la comunidad de la que se forma parte. Por consiguiente, el deber de auxilio, que otorga el fundamento de legitimación a la norma sobre omisión de socorro, tiene claramente un alcance intersubjetivo en el sentido de que obliga en la relación directa entre personas -vis á vis-. En cambio, el deber de colaboración, que constituye el fundamento del tipo del art. 496 N. 2 CP, deriva abiertamente de la competencia y tareas propias del Estado, derivación que a su vez se funda en la condición del sujeto de ser miembro de la comunidad jurídicamente organizada ${ }^{19}$.

Este ejercicio de comparación entre ambos tipos permite confirmar la existencia de un deber general de solidaridad en sentido estricto y, en principio, con un fundamento autónomo ${ }^{20}$.

17 En este sentido, Pawlik, 1995, p. 363 y s., respecto del § 323 c del Código Penal alemán; sin embargo, es importante tener presente que el supuesto fáctico de este tipo de omisión de socorro incluye expresamente la hipótesis de "peligro general" junto con la situación de peligro (individual) y de necesidad; posteriormente, PAWLIK, 2012, p. 191 y s., complementa la fundamentación del deber de socorro con la idea general que subyace al Derecho de seguro, pensando, por cierto, en el sistema público de seguridad social arraigado en el Estado de bienestar; en consecuencia, no se trata de un deber que se tiene directamente con el conciudadano que cae en una situación de peligro - no se trata, entonces, de un deber puro de solidaridad intersubjetiva-, sino que de un deber que se tiene frente al conjunto de los ciudadanos y que se cumple, por ende, en representación de la comunidad para con la víctima.

${ }^{18}$ No traza esta diferenciación PIÑA, 2010, p. 149 y s.

19 Cfr. art. 43 inc. $3^{\circ}$ Constitución Política de la República sobre facultades del Presidente de la República en un estado excepcional de catástrofe.

${ }^{20}$ En una perspectiva histórico-legislativa, la norma del art. 496 N. 2 CP se menciona por primera vez en la sesión número 112 del trabajo de la comisión redactora del CP. En ella, el precepto estaba numerado como art. 481 N. 5 y a su respecto se señaló que debía incorporarse la frase "sin grave detrimento propio", con el fin de no volver "ilusoria” la disposición, ASCR, sesión 112, 24 de agosto de 1872. De este modo, se reproducía la norma contenida en el art. 494 N. 2 del CP español de 1850. A su vez, el origen histórico comparado de esta última norma se remonta al Código Penal francés de 1810, específicamente a su artículo 475 N. 12, ver también PIÑA, 2010, p. 400, nota 558. Respecto de esta hipótesis, se ha dicho que estaba vinculada más bien con un supuesto de omisión frente a la autoridad y no así, propiamente, con 


\section{Figuras Relacionadas CON LA IDEA DE SOLIDARIDAD EN LA LEGISLACIÓN ESPECIAL: LEY DE NAVEGACióN (ART. 102 y ART. 112) y LEY DE TRÁNSITO (ART. 195)}

El objeto del análisis precedente es solamente identificar el espacio que ocupa el deber general de solidaridad hasta ahora en la parte especial del Código Penal. Como se ve, la dimensión de la "solidaridad intersubjetiva" es bastante acotada al menos en esta parte de la legislación penal.

Esa aproximación se confirma al revisar la figura de omisión de denuncia sancionada en el art. 177 del Código Procesal Penal (en adelante: CPP) con la misma pena de falta del art. 494 CP. En la dogmática alemana se suele relacionar el tipo de omisión de socorro del §323 c Código Penal alemán (en adelante: StGB) con la figura de omisión de denuncia tipificada en los $\$ \$ 138$ y 139 del mismo código, porque se encuentra en el deber general de solidaridad un fundamento que sería común a ambas normas ${ }^{21}$. Lo mismo sucede en la doctrina española cuando esta relaciona la norma del art. 195 acerca de omisión de socorro con la del art. 450 del CP español respecto de omisión de denuncia. Sin embargo, esta relación se traza porque ambos tipos de omisión de denuncia se refieren a hechos constitutivos de un delito grave aún por cometerse y respecto de ello todo ciudadano se encuentra obligado a intervenir mediante denuncia, en lo posible antes de su realización -o a más tardar durante la misma-. En cambio, la norma pertinente a omisión de denuncia de los artículos 175 y 176, cuya infracción se encuentra sancionada por el art. $177 \mathrm{CPP}$ antes citado, resulta aplicable solamente respecto de aquellos sujetos que se encuentran obligados especialmente a denunciar, según el art. 175, y, además, dentro de un plazo de 24 horas "siguientes al momento en que tomaren conocimiento del hecho criminal” -art. $176 \mathrm{CPP}$-, por esta razón, este tipo se refiere a hechos delictivos previamente cometidos.

El fundamento de esta norma, en consecuencia, no radica en un deber general de solidaridad cuyo sentido consistiría en evitar la realización de una situación de peligro para bienes jurídicos o la comisión de un delito. Más bien su fundamento podría encontrarse en un deber de colaboración, pero no con el cumplimiento de las tareas propias del Estado frente a los peligros generales y al delito, sino que solamente con el funcionamiento del sistema de justicia criminal ${ }^{22}$. De ahí su clasificación entre los delitos contra la "administración de justicia" y también su restricción a los sujetos especiales del art. 175 CPP.

el de omisión de socorro, diversa procedencia que implicaría un fundamento distinto, ver Cuello, 1951, pp. 335-340. A partir de ese origen, la norma vuelve a aparecer en el CP español de 1848 como artículo 481 N. 2 y, finalmente, en el CP español de 1850 como artículo 494 N. 2.

${ }^{21}$ Cfr. Rojas, 2017, pp. 147 y ss.

${ }^{22}$ Cfr. SÁnchez-Ostiz, 2004, pp. 213 y ss., p. 348 y s., 370. 


\section{1. ¿Solidaridad en la navegación?}

A causa de que hasta el momento solo se han encontrado algunas manifestaciones del deber general de solidaridad en el acápite sobre faltas del Código Penal, parece necesario seguir en la búsqueda de otros tipos ahora fuera del mismo, vale decir, en la farragosa legislación especial. Lo anterior, también porque sería algo frustrante acotar el presente trabajo a la explicación del fundamento de meras faltas penales -a una "dogmática de las faltas"-.

En este ámbito de la legislación, es admisible mencionar la norma del art. 102 de la Ley de Navegación (Decreto Ley N. 2.222, de 1978: en adelante, LN), que obliga al capitán de nave a acudir en auxilio de otra nave en peligro, en los términos siguientes:

Art. 102 LN: "Toda nave tiene la obligación de acudir en auxilio de otra en peligro, salvo que ello represente un grave riesgo para su propia seguridad, la de su dotación o la de sus pasajeros.

Esta obligación cesa en cuanto se haya logrado asegurar la vida de la dotación y de los pasajeros de la nave en peligro. El capitán que no cumpliere con este deber, será sancionado con la cancelación de su título, sin perjuicio de la responsabilidad penal que le afecte, a menos que justifique haber tenido una causa que razonablemente le haya impedido hacerlo.

El armador o naviero no será responsable en este caso por el hecho de su capitán”.

Esta norma se refiere a la situación en la que una nave se encuentra con otra en peligro, de modo tal que parte de la premisa de una obligación recíproca de socorro $-v \cdot g r$.: art. 1135 Código de Comercio-. La referencia expresa al aseguramiento de la vida de la dotación y los pasajeros de la nave en peligro evidencia que su fin radica en la protección de este bien jurídico ${ }^{23}$. No obstante, en el caso de incumplimiento de esta obligación, y

${ }^{23}$ En el origen de la legislación marítima nacional, concerniente a los “deberes de auxilio", existía únicamente este supuesto de "asistencia marítima” y no el contemplado en el actual art. 112 LN para el caso de abordajes. En efecto, la fuente histórica de la legislación marítima nacional es la Ley General de Navegación de 1836 , ley que tenía principalmente por objeto reglamentar la nacionalidad de los barcos, sin referencias a la asistencia marítima, ver: Humeres, 1966, p. 26; Ansieta, 1983, p. 118. Algunas décadas más tarde, se promulga la Ley de Navegación de 1878 donde se reconocen por primera vez los deberes de asistencia y salvamento marítimos, entonces previstos en el art. $130 \mathrm{LN}$; su incumplimiento se castigaba, sorpresivamente, conforme con lo dispuesto en el art. 492 CP (ver: Biblioteca del Congreso Nacional, 1878, p. 40; cfr. Ansieta, 1983, p. 121; Humeres, 1966, p. 14). Luego, en esta línea histórica, el 23 de septiembre de 1910 se celebraron en Bruselas dos convenios internacionales referentes a la materia en estudio; en el primero de ellos se unificaron las reglas de los Estados relativas a los casos de auxilio y asistencia marítima y, en el segundo, las reglas vinculadas a los casos de abordaje, que serían de suma importancia para la legislación venidera. Posteriormente, en 1978, se dictó el Decreto Ley N. 2.222 con el objeto tanto de unificar y actualizar la legislación marítima como de recoger las directrices internacionales en la materia (particularmente, los convenios de Bruselas), insertando la regulación de la asistencia marítima en el art. 102 y de la situación de abordaje en el art. 112 LN (Biblioteca Congreso Nacional, 1978, "Mensaje”, p. 309 y s.). En relación con el art. $102 \mathrm{LN}$, se declaró, al informar acerca del título VIII del proyecto titulado "Riesgos de la 
para los efectos de la sanción a imponer, además de la cancelación del título de capitán, la norma remite a la responsabilidad penal que corresponda, sin aclarar la clase de responsabilidad a la que se refiere. En principio, esta no sería otra que la responsabilidad correspondiente a la omisión de socorro tipificada en el art. 494 N. 14 CP.

Otra norma pertinente de la Ley de Navegación es la contemplada en el art. 112 que, a diferencia de la disposición previamente citada, regula los deberes que han de cumplirse en una situación de colisión o abordaje entre naves:

Art. 112 LN: "Al producirse una colisión o abordaje entre naves, el capitán de cada una estará obligado a prestar auxilio a la otra, a su dotación y a sus pasajeros, siempre que pueda hacerlo sin grave riesgo de su nave y de las personas a bordo.

Igualmente, cada capitán debe dar al otro las informaciones necesarias para su identificación.

El capitán que, sin causa justificada, no cumpliere con lo dispuesto en el inciso primero, será sancionado con la cancelación de su título, sin perjuicio de la responsabilidad penal que pueda afectarle por este mismo hecho.

El armador de la nave no será responsable del incumplimiento por parte del capitán de las obligaciones que le impone este artículo”.

La norma cuya infracción se encuentra sancionada en el inciso $3^{\circ}$ extiende la obligación de auxilio a una situación de colisión o abordaje entre naves -definida en el art. 1116 del Código de Comercio ${ }^{24}$ - . Aquí el equívoco en el que puede incurrirse, si la norma se lee precipitadamente desde la óptica de la dogmática jurídico-penal, es pensar que regula una hipótesis de injerencia, en el sentido de una posición de garantía para los efectos de la omisión impropia. Sin embargo, la situación de colisión o abordaje, que activa la obligación general preexistente de auxilio, puede haber sido causada tanto por caso fortuito o fuerza mayor como por culpa de una de las naves -art. 1120 Código de

\footnotetext{
Navegación y Servicios del Mar", que se mantenían los principios del deber de socorro para todo navegante, con la prevención, no obstante, de haberse suprimido de la legislación marítima la denominación del párrafo respectivo como de auxilio, asistencia o salvamento, con el fin de unificar la prestación bajo el rótulo de "los servicios prestados a la nave que está en peligro", con lo que el art. 102 LN se incorporaba definitivamente en el actual párrafo primero sobre "reglas generales" del título VIII (Biblioteca Congreso NaCiOnAL, 1978, "Mensaje", p. 315 y s.).

${ }^{24}$ Es importante recordar que la omisión de auxilio en casos de abordaje aparece recién en la legislación mediante el Decreto Ley N. 2.222, de 1978, sin que se encuentre este supuesto en leyes marítimas anteriores, ver nota 23. Además, conviene tener en cuenta que, al informarse respecto del proyecto del Decreto Ley $\mathrm{N}$. 2.222, se incorporó un epígrafe llamado “Abordajes”, en el que se incluiría definitivamente la disposición del actual art. 112 LN. Respecto de este epígrafe, se señaló que la materia en estudio modificaba las antiguas reglas del Código de Comercio, "dándose cabida a normas de mayor uso en el mundo marítimo y que provienen de la Convención Internacional sobre Indemnización de Perjuicios causados en Abordajes, suscrita en Bruselas en 1910”. De este modo, la distribución de los daños en casos de abordaje se fijaba en "proporción a la gravedad de la culpa que el tribunal asigne a cada responsable”, además de establecer que la prueba se apreciaría en consciencia (Biblioteca Congreso Nacional, 1978, "Mensaje", p. 315 y ss.). Finalmente, el 31 de mayo de 1978, la regla entró en vigencia mediante la publicación del Decreto Ley en comento.
} 
Comercio-. El deber de auxilio se encuentra formulado en los términos de una obligación recíproca entre las naves que se encuentran en una situación de colisión o abordaje. El incumplimiento de esta obligación genera, según ordena la disposición del inciso $3^{\circ}$, además de la cancelación del título de capitán, responsabilidad penal, sin que la norma misma aclare de qué clase de responsabilidad se trata. Por tanto, esta podría consistir en la responsabilidad por un delito impropio de omisión, cuya posición de garante se funda en la injerencia por haber provocado la colisión, o simplemente en la responsabilidad propia del tipo general de omisión de socorro, en los demás casos.

Ahora bien, y esto es relevante para comprender el alcance de la siguiente y última norma a comentar en el marco del presente trabajo, el precepto del inciso $2^{\circ}$ del art. 112 LN impone, además del deber de auxilio, la obligación también recíproca de dar información al otro que permita la identificación personal del capitán de nave $-v \cdot g r$ : art. 911 del Código de Comercio-. En este aspecto se plantea la siguiente pregunta: ¿para qué efectos se impone esta obligación adicional de dar información al otro en el caso de colisión o abordaje? Pues bien, la respuesta surge de la lectura de las reglas sobre abordaje de los artículos 1116 y siguientes del Código de Comercio, que regulan fundamentalmente la responsabilidad civil generada en tales situaciones. Fin y sentido, entonces, de la norma del art. 112 inciso $2^{\circ} \mathrm{LN}$ radica en asegurar, mediante el cumplimiento de esa obligación de informar, el ejercicio de acciones civiles por los daños producidos a consecuencia de la colisión o abordaje, acciones que no podrían ejercerse en el caso de ni siquiera saber quién es el otro capitán de nave -mientras que el deber de auxilio puede cumplirse de manera perfectamente anónima-.

\section{2. ¿Solidaridad en el tráfico rodado?}

Finalmente, y para concluir este panorama, conviene revisar el alcance de la norma del art. 195 de la Ley de Tránsito (en adelante: LT), cuyo texto fue reformulado por la muy conocida Ley $\mathrm{N}^{\circ} 20.770$ :

Art. 195 LT: "El incumplimiento de la obligación de dar cuenta a la autoridad de todo accidente en que solo se produzcan daños, señalada en el artículo 168, será sancionado con multa de tres a siete unidades tributarias mensuales y con la suspensión de la licencia hasta por un mes.

El incumplimiento de la obligación de detener la marcha, prestar la ayuda posible y dar cuenta a la autoridad de todo accidente en que se produzcan lesiones, señalada en el artículo 176, se sancionará con la pena de presidio menor en su grado medio, inhabilidad perpetua para conducir vehículos de tracción mecánica y multa de siete a diez unidades tributarias mensuales.

Si en el caso previsto en el inciso anterior las lesiones producidas fuesen de las señaladas en el número $1^{\circ}$ del artículo 397 del Código Penal o se produjese la muerte de alguna persona, el responsable será castigado con la pena de presidio menor en su grado máximo, inhabilidad perpetua para conducir vehículos de tracción mecánica, multa de once a veinte unidades tributarias mensuales y con el comiso del vehículo 
con que se ha cometido el delito, sin perjuicio de los derechos del tercero propietario, que podrá hacer valer conforme a las reglas generales del Código Procesal Penal. Para los efectos de determinar la pena prevista en este inciso, será aplicable lo dispuesto en los artículos 196 bis y 196 ter de esta ley.

Las penas previstas en este artículo se impondrán al conductor conjuntamente con las que le correspondan por la responsabilidad que le pueda caber en el respectivo delito o cuasidelito, de conformidad con lo dispuesto en el artículo 74 del Código Penal”.

Sin todavía pretender analizar exhaustivamente esta norma, es necesario detenerse un momento en el alcance del tipo del art. 195 inciso $2^{\circ} \mathrm{LT}$, pues este se encuentra construido también sobre la base de la infracción a un deber de prestar ayuda en el caso de un accidente de tránsito con resultado de lesiones corporales ${ }^{25}$. En esta medida, por cierto que el fin y sentido del deber de prestar ayuda atañe a la protección de la salud y la vida de la víctima del accidente de tránsito frente al peligro originado en las lesiones corporales de un daño mayor a la salud o incluso para la vida de aquella ${ }^{26}$. Este deber, y solamente en esta medida, puede justificarse desde una perspectiva de un deber general de solidaridad ${ }^{27}$. Pero el injusto del hecho descrito en este tipo base se funda antes bien en el incumplimiento de la obligación de dar cuenta a la autoridad policial. Ambos deberes se encuentran previstos por el art. 176, disposición a la que remite expresamente el art. 195 inciso $2^{\circ}$ LT, frente a "todo accidente del tránsito en que se produzcan lesiones o muerte". El sentido del deber de prestar ayuda parece claro, no lo es, empero, el de la obligación de dar cuenta a la autoridad policial ${ }^{28}$. Para esclarecerlo, es preciso tener presente varios aspectos que surgen de una lectura desprejuiciada del texto de la norma ${ }^{29}$.

25 Cfr. van WeEZel, 2014, pp. 194 y ss.

${ }^{26}$ En este sentido, Matus y Ramírez, 2017, p. 220 y s.

${ }^{27}$ En este sentido, ya la Corte de Apelaciones de Temuco señaló, respecto del entonces art. 69 de la Ley $\mathrm{N}^{\circ} 15.231$ (norma que contenía los deberes incluidos en el artículo 176 de la actual LT), que la razón de las obligaciones allí previstas se fundamentaban en "obligaciones mínimas de humanidad y comportamiento social”, ver: Revista de Derecho y Jurisprudencia, tomo LXVII, sección IV, trámite de consulta, sentencia de 01.10.1970, Corte de Apelaciones de Temuco, pp. 387-396.

${ }^{28} \mathrm{La}$ jurisprudencia reciente referente al punto ha considerado que los tres deberes establecidos en la norma estarían dirigidos a proteger la vida y salud de las víctimas, incluido el deber de dar cuenta a la autoridad. Por eso, a su vez, se trataría de deberes de cumplimiento copulativo. Véase: Corte de Apelaciones de Punta Arenas, 30.05.2016, rol 59-2016, resolución N. 13760, cdo. 3º; Corte de Apelaciones de Punta Arenas, 30.05.2016, rol 60-2016, resolución N. 13755, cdo. 3º; e implícitamente, Corte de Apelaciones de La Serena, 16.03.2016, rol 37-2016, resolución N. 10751, cdos. $4^{\circ}$ y $5^{\circ}$. De otra opinión, Corte de Apelaciones de La Serena, 30.05.2016, rol 156-2016, cdo. 5º en tanto se trataría de "un solo deber con tres acciones, todas destinadas a la protección de la víctima y colaborar con la acción persecutora del Estado".

${ }^{29} \mathrm{El}$ art. 195 inc. $2^{\circ}$ LT surge de la siguiente forma: fue en la Ley $\mathrm{N}^{\circ} 15.123$, de 1963 , donde aparecen por primera vez los deberes de detener la marcha, prestar la ayuda necesaria y dar cuenta a la autoridad más inmediata de todo accidente de tránsito en el que se produjesen lesiones o muerte, cuya contravención era catalogada como una "presunción de culpabilidad" (art. 60). Luego, en el seno de las discusiones sobre la Ley $\mathrm{N}^{\circ}$ 18.290, de 1979, cuando se discutía acerca de elevar dicha presunción a la categoría de delito, se 
En primer lugar, se trata de una obligación de dar cuenta a la autoridad policial para los efectos de que esta luego denuncie, ya sea al Juzgado de Policía Local o al Ministerio Público -art. 178 LT-. Por consiguiente, no se impone una obligación de denunciar ni menos de autodenunciarse, sino que solo de dar información a la autoridad policial ${ }^{30}$. El problema es que la propia LT no determina exactamente qué información debe darse a la autoridad. A este respecto, el texto tanto del art. 195 como del art. 176 LT precisa solamente que debe darse cuenta "de todo accidente del tránsito" con tal clase de consecuencias, es decir, se debe informar del hecho de un accidente del tránsito con tales resultados. En particular, no existe una obligación similar a la contemplada en el art. 112 inciso $2^{\circ} \mathrm{LN}$ de identificación. No obstante, en la medida en que los deberes se imponen al "conductor que participe en los hechos", se sigue de esta referencia que el sujeto debe también informar acerca de que ha tenido participación en tal condición en el accidente de tránsito.

La pregunta que sigue atañe a los fines de esta obligación de dar cuenta a la autoridad policial. En este punto, conviene tener presente la ubicación de la norma de remisión del art. 176 en el título XVI sobre "procedimientos policiales y administrativos" LT, a continuación del título sobre "responsabilidad por los accidentes" de la misma ley. Esta consideración sistemática interna a la LT permite sostener la tesis que los fines de esta obligación dicen relación, primero, con posibilitar a los órganos del Estado iniciar un proceso para esclarecer la responsabilidad contravencional y eventualmente penal implicada y, segundo, con permitir a los interesados el ejercicio de acciones civiles por el daño producido -art. $165 \mathrm{LT}^{31}-$.

insertó un art. 183 que establecía como obligaciones del conductor, que ocasionare un accidente del tránsito (únicamente) con lesiones, detener la marcha, prestar ayuda a los afectados y dar cuenta a la autoridad policial más inmediata, Biblioteca del Congreso Nacional, 1984, p. 118. El incumplimiento de estos deberes era castigado, en el art. 196 N. 16, como una contravención menos grave, con la pena de multa, BiBLIOTECA Del Congreso Nacional, 2005, p. 511 y s. A continuación, en el seno de las discusiones sobre la Ley No 20.068, específicamente, en el segundo informe de la Comisión de Obras Públicas de 1999, se presentó una moción que tenía por objeto elevar dicha infracción a la categoría de simple delito, agregando un inciso final al entonces art. 183 (actual art. 176). Sin embargo, en el contexto del segundo trámite constitucional de 2004, primó el criterio en orden a incorporar las penas para esos supuestos fácticos en un artículo autónomo, Biblioteca del Congreso Nacional, 2005, p. 581, pp. 623 y ss. De esta manera, surgió un art. 196 D1 que sancionaba la infracción de esos deberes, y solamente para la hipótesis con lesiones, como un simple delito, Biblioteca del Congreso Nacional, 2005, p. 678. Por último, ya en la tramitación de la Ley $\mathrm{N}^{\mathrm{o}} 20.770$, vuelve a aparecer la hipótesis de accidente con resultado de muerte. En efecto, fue en el contexto de la tramitación de esta ley donde se configura el art. 195 con una hipótesis de lesiones, por un lado, y con la de lesiones del art. 397 N. 1 CP, y muerte, por el otro. Esta última configuración aparece mediante una moción, según esta, era necesario distinguir las penas en virtud de los resultados producidos, pues de otra manera se favorecía la huida del lugar del accidente, Biblioteca del Congreso Nacional, 2014, p. 83. De esta forma, se procuraba tanto desfavorecer la impunidad del delito como también auxiliar a la víctima, Biblioteca del Congreso Nacional, 2014, pp. 121-123 y p. 157.

${ }^{30}$ De otra opinión Valenzuela, 2015, pp. 136 y ss., quien ve en este tipo una especie del delito de omisión de denuncia.

31 Al respecto, con mayor detalle, RojAs, 2018. 
En este sentido, y si uno se fija bien, el presupuesto fáctico del tipo base del art. 195 LT se encuentra descrito en términos muy diferentes que el presupuesto del deber de socorro en el art. 494 N. 14 CP. Este último tipo describe una situación de peligro, en cambio el tipo base del art. 195 LT describe un hecho consistente en un accidente del tránsito que ya ha producido lesiones corporales. Allá el momento determinante para el cumplimiento del deber de socorro es anterior a la realización del peligro, mientras que aquí el momento decisivo para el cumplimiento del deber es posterior al suceso del accidente de tránsito con tales consecuencias. Asimismo, debe informarse de "todo accidente del tránsito" con resultado de lesiones corporales en el que se haya participado como conductor, es decir, con independencia de la circunstancia de haber causado o no el accidente ${ }^{32}$. Por consiguiente, y como puede verse, no se trata aquí tampoco de una hipótesis de injerencia en el sentido de la dogmática de las posiciones de garante, que se encontraría especialmente legislada. Lo que ocurre es que si a partir de las lesiones corporales provocadas por el accidente, causado o no por el sujeto, deriva a su turno un peligro de daño mayor a la salud o incluso para la vida de otro, el art. 176 LT impone razonablemente además el deber de prestar la ayuda posible a la víctima del accidente.

Ahora bien, el cumplimiento de la obligación de dar cuenta a la autoridad policial del accidente de tránsito sirve a un interés jurídico distinto que la protección de la vida y la salud del otro participante en el suceso. Dicha obligación tiene un fundamento propio, que se vincula antes bien con la idea de "administración de justicia”. Pues, la comunicación a la autoridad policial funge solamente como una vía para canalizar el conflicto surgido del accidente ante un órgano jurisdiccional -la información recibida sobre el accidente de tránsito y la participación del sujeto en el mismo no se queda atascada en sede policial. Además, el art. 176 LT impone explícitamente el deber de detener la marcha, deber que solo tiene sentido frente al riesgo de que, luego de ocurrido un accidente, el sujeto abandone raudamente el lugar del suceso, sin que pueda esclarecerse su eventual responsabilidad civil, administrativa o penal eventualmente implicada. En el marco de esta norma, el incumplimiento del deber de ayuda adquiere una relevancia secundaria. El injusto propio de la figura surge del incumplimiento del deber de detener la marcha y de la obligación de dar cuenta a la autoridad policial del suceso del accidente. No se trata, en fin, de un delito de "omisión de auxilio en el tráfico rodado", sino que de un delito de abandono del lugar del accidente de tránsito.

${ }^{32}$ Cfr. la siguiente jurisprudencia: Corte de Apelaciones de Punta Arenas, 30.05.2016, rol N. 59-2016, resolución N. 13760, cdo. $3^{\circ}$; Corte de Apelaciones de Punta Arenas, 30.05.2016, rol N. 60-2016, resolución N. 13755 , cdo. $3^{\circ}$. De otra opinión: Corte de Apelaciones de Concepción, 11.03.2016, rol N. 77-2016, resolución N. 54743, cdo. $4^{\circ}$ y 5, según la cual, el art. 195 de la LT estaría dirigido a los conductores bajo los efectos del alcohol o en estado de ebriedad que causaren el accidente, mientras que sería la norma del artículo 201 N. 15 de la LT, la dirigida a todo participante en el accidente de tránsito. 


\section{CONCLusión}

El análisis precedente permite arribar a la siguiente conclusión. En el ámbito de la parte especial del Derecho penal chileno, la única norma cuyo fundamento radica en un deber puro de solidaridad, entendido en el sentido estricto de un deber que obliga en la relación intersubjetiva entre ciudadanos, es la norma que subyace al tipo general de omisión de socorro del art. 494 N. 14 CP. El fundamento de las demás normas estudiadas, o bien supone la relevancia del deber de un tercero (familia o Estado) - v.gr.: art. 494 N. 13, art. 496 N. 2 CP- o su explicación surge de un contexto fáctico específico, ya sea que se trate de la navegación -v.gr.: art. 102, art. 112 LN- o del tráfico rodado -art. 195 LT-.

\section{BiBLIOGRAFÍA}

Ansieta, Alfonso, 1983, "Las grandes líneas de la historia del Derecho Marítimo", Revista de Derecho (PUCV) $\mathrm{N}^{\circ} 7$.

Antón Oneca, José, 1965, "El Código Penal de 1848 y D. Joaquín Francisco Pacheco”, Anuario de Derecho Penal y Ciencias Penales, tomo XVIII, Fasc. III, pp. 473-495.

ArÁuz, Manuel, 2006, El delito de omisión al deber de socorro, Aspectos fundamentales, Valencia: Tirant lo Blanch.

BAyertz, Kurt, 1998, "Begriff und Problem der Solidarität”, en Bayertz (ed.), Solidarität, Begriff und Problem, Frankfurt a.M.: Suhrkamp, pp. 19-51.

Cuello, Eugenio, 1951, "La obligación de socorrer a las personas en peligro en la legislación penal española (El nuevo artículo 489 bis del Código penal Ley $\mathrm{N}^{\circ} 17$ de julio de 1951)", Anuario de Derecho Penal y Ciencias Penales, tomo IV, Fasc. II, pp. 335-340.

Depenheuer, Otto, 1991/2009, Solidarität im Verfassungsstaat, Norderstedt: Books on Demand $\mathrm{GmbH}$.

GuZMÁn, José Luis, 2013, "Reseña histórica de la Codificación penal y procesal penal en Chile", en MAÑALICH, J.P. (coord.), La ciencia penal en la Universidad de Chile, Santiago: sin editorial, pp. 105-129.

Hegel, G.W.F., 1970, Grundlinien der Philosophie des Rechts, Frankfurt a.M.: Suhrkamp.

Humeres, Luis, 1966, Derecho Marítimo, Santiago: Jurídica de Chile.

Insunsa, Sergio, 1970, "Corte de Apelaciones de Temuco, Sentencia 01.10.1970", Revista de Derecho y Jurisprudencia y Ciencias Sociales y Gaceta de los Tribunales, tomo LXVII, sección IV.

Marquard, Odo, 2015, Abschied vom Prinzipiellen, Stuttgart: Reclam.

Matus, J. y Ramírez M.C., 2017, Manual de Derecho penal chileno. Parte especial, Valencia: Tirant lo Blanch.

Navas, Iván, 2015, "Acción y omisión en la infracción de deberes negativos en derecho penal", Política Criminal, vol. 10, No 20, pp. 678-693.

PAWLIK, Michael, 1995, "Unterlassene Hilfeleisteung: Zuständigkeitsbegründung und systematische Struktur”, Goltdammer's Archiv für Strafrecht, pp. 360-372.

PAwlik, Michael, 2012, Das Unrecht des Bürgers, Tübingen: Mohr/Siebeck.

PIÑA, Juan Ignacio, 2010, Derecho penal. Fundamentos de la responsabilidad, Santiago: Abeledo Perrot.

Politoff, S.; Grisolía, F.; Bustos, J., 1993, Derecho penal chileno. Parte especial. Delitos contra el individuo en sus condiciones físicas, $2^{\mathrm{a}}$ ed., Santiago: Editorial Jurídica de Chile. 
Rawls, John, 1975, Eine Theorie der Gerechtigkeit, Frankfurt a.M.: Suhrkamp.

Rivacoba y Rivacoba, M.; Quezada, V. y Guzmán, C. (coords.), 1974, “Actas de las sesiones de la Comisión Redactora del Código Penal”, en Código Penal de la República de Chile y Actas de las sesiones de la comisión redactora, con un estudio preliminar por Manuel de Rivacoba y Rivacoba, Valparaíso: Edeval.

Rodríguez Mourullo, Gonzalo, 1996, La omisión de socorro en el Código Penal, Madrid: Tecnos.

Rojas A., Luis Emilio, 2017, "Grundprobleme der allgemeinen Verbrechenslehre bei der unterlassenen Verbrechensanzeige - §§ 138, 139 StGB“, Goltdammer's Archiv für Strafrecht, pp. 147-161.

Rojas A., Luis Emilio, 2018, "Fundamento y estructura del delito contemplado en el art. 195 de la Ley de Tránsito", Revista Ius et Praxis, vol. 2, diciembre.

SÁnchez-Ostiz, Pablo, 2004, ¿Encubridores o cómplices? Contribución a una teoría global de las adhesiones post-ejecutivas, Madrid: Editorial Civitas.

Valenzuela, Jonatan, 2015, "Omisión de dar cuenta a la autoridad policial y negativa injustificada a someterse a exámenes corporales desde una perspectiva constitucional y procesal”, Informes en Derecho, Defensoría Penal Pública.

Van Weezel, Alex, 2014, "Solidaridad en el tráfico motorizado", Doctrina y jurisprudencia penal, año 5, número especial, pp. 191-204.

VAn Weezel, Alex, 2016, "Necesidad justificante y solidaridad”, en Cárdenas, C. y Ferdman, J. (coords.), El Derecho penal como teoría y como práctica, Santiago: Thomson Reuters, pp. 213-230.

Wilenmann, Javier, 2014a, Freibeitsdistribution und Verantwortungsbegriff, Tübingen: Mohr Siebeck.

WilenmanN, Javier, 2014b, "El fundamento del estado de necesidad justificante en el derecho penal chileno. Al mismo tiempo, introducción al problema de la dogmática del estado de necesidad en Chile", Revista de Derecho (Valdivia), vol. XXVII, No 1, pp. 213-244.

WilenmanN, Javier, 2016, "Sobre la estructura argumentativa de los delitos de omisión impropia”, en Cárdenas, C. y Ferdman, J. (coords.), El Derecho penal como teoría y como práctica, Santiago: Thomson Reuters, pp. 275-322.

Jurisprudencia citada

Corte de Apelaciones de Temuco, 01.10.1970, Revista de Derecho y Jurisprudencia, tomo LXVII, sección IV, trámite de consulta.

Corte de Apelaciones de Punta Arenas, 30.05.2016, rol 59-2016.

Corte de Apelaciones de Punta Arenas, 30.05.2016, rol 60-2016.

Corte de Apelaciones de La Serena, 16.03.2016, rol 37-2016.

Corte de Apelaciones de La Serena, 30.05.2016, rol 156-2016.

CorTe de Apelaciones de Concepción, 11.03.2016, rol No 77-2016.

\section{Normas citadas}

Biblioteca del Congreso Nacional, 1877: Proyecto de ley de navegación aprobado por la Cámara de Diputados.

Biblioteca del Congreso Nacional, 1978: Historia Decreto Ley No 2.222.

Biblioteca del Congreso Nacional, 1984: Historia de la Ley $\mathrm{N}^{\circ} 18.290$.

Biblioteca del Congreso Nacional, 2005: Historia de la Ley No 20.068.

Biblioteca del Congreso Nacional, 2014: Historia de la Ley No 20.770.

Código Penal, República de Chile, Edición Oficial. 